\title{
Auditing the Siting of Petrol Stations in the City of Douala, Cameroon: Do they Fulfil the Necessary Regulatory Requirements?
}

Samuel Batambock, Ndoh Mbue Innocent*, Dieudonné Bitondo, Augusto Francisco Nguemtue Waffo

University of Douala, Department of Industrial Quality, Hygiene, Safety, and Environment, ENSPD, Douala, 2701, Cameroon

\begin{tabular}{l} 
A R T I C L E I N F O \\
\hline Article history: \\
Received: 23 November, 2020 \\
Accepted: 09 January, 2021 \\
Online: 28 January, 2021 \\
\hline
\end{tabular}

Keywords:

Petrol Stations

City of Douala

Nearest Neighbourhood Index

\begin{abstract}
A B S T R A C T
No other form of technological development had negatively skewed from existing regulations as the siting of petrol filing stations. An audit of the degree to which their operators repeatedly violate the rules regulating their location and operations may encourage the legislature to pass laws that can ensure a balance between the economy and the environment. This study helps to fill this gap, by analyzing the degree to which the siting of local filling stations meets standard norms, taking Cameroon's district municipalities of Douala as an example. In order to achieve this goal, the current regulations structuring the filling station locations were carefully reviewed. Subsequently, key compliance factors were identified, operationalized, and an audit checklist was developed. Other data collection tools included a structured questionnaire designed to capture the views of neighboring communities on the possible risks to their health, land, and therefore to the environment presented by the station, and a global positioning system receiver for the collection of spatially explicit data. The nearest neighbourhood Index, (Rn) in ArcGIS10.3.1 environment was used to assess the distribution pattern of the stations. Questionnaire data was analysed using SPSS20.0. It is revealed that the distribution pattern of the 152 stations surveyed is mostly random in Douala I $(R n=0.8573)$, Douala III $(R n=0.9879)$, Douala IV $(R n=0.6984)$, and, dispersed in Douala II $(R n=1.7837)$ and Douala V $(R n=1.5764)$ district municipalities. While most of them, 94 (61.84\%) were within the minimum $500 \mathrm{~m}$ radius from one another as specified by laws, 99.34\% of them didn't conform with the recommended minimum distance of $7 \mathrm{~m}$ from the centre of a major road, and the $400 \mathrm{~m}$ radius from residential areas. The results suggest that the siting of petrol stations in the city neglect the hazards accompanying them. The database created in this study could provide a platform to policy makers for appropriate actions.
\end{abstract}

\section{Introduction}

A major concern in contemporary literature remains the continuing proliferation of oil and gas stations in urban areas. In the current technological society, they are necessary, but explosions from such facilities frequently trigger loss of life and property within the surrounding communities, thereby presenting great concern to the government and people. Concerns are also raised about the ecosystem's health, protection and environmental quality resulting from these facilities [1]. Petrol vapour, for example, may ignite when exposed to sparks from sources such as lighted cigarettes or a static electrical discharge [2]. The site of petrol stations must therefore be strategically planned to mitigate their effect on both humans and their immediate surroundings [3].

\footnotetext{
* Corresponding Author: Ndoh Mbue Innocent, Univ. of Douala,

+237653754070, dndoh2009@gmail.com

www.astesj.com
}

https://dx.doi.org/10.25046/aj060154
Otherwise, referred to as petrol stations [4]-[5], gas station [6], filling station [7], an oil and gas station is defined as any land, building or equipment used for the sale or dispensing of petrol or oil for motor vehicles [5], Most filling stations sell petrol or diesel, some carry specialty fuels such as liquefied petroleum gas, natural gas, hydrogen, biodiesel, kerosene, or butane while others add shops to their primary business [8]. Because their products are flammable, filling stations pose a constant hazard to the staff, public, assets, and environment. They therefore, need special care in their design, construction, installations, and operations, so that, they remain safe and secure throughout their lifespans. An optimal site selection can enhance the security of the station and its environs. Conversely, a poorly selected site could cause detrimental effects on the stations, and their environs [9]. It is 
therefore, important to access their locational compliance with regulatory requirements..

Historically, the inappropriate location of petrol stations has led to disasters. For example, in 2004, more than 2.3 million lives and properties worth about 4.5 billion was lost to fire outbreaks due partly to poor location and mishandling of petroleum products [4]. A similar incident occurred at a liquefied gas filling station and a nearby petrol station in the Kwame Nkrumah Circle claiming 150 lives[10]-[11]. Several other authors have evoked the underlying and proximate causes leading to hazards in filling stations including, fire hazard [12], static electricity [13], and traffic jam [14]. Leakages of pipes \& underground storage tanks have been identified to result in the contamination of both surface, and underground water, and air pollution [6]. In this context, petrol stations present health, and safety concerns, especially the potential for fires owing to the toxicity and flammability of the liquid and gaseous products.

Following this, several other studies have assessed the relationship between the location of petrol stations and existing policies, e.g., [15]-[16], and their impacts on the environment [4]. Other authors like [17] and [18], have opined that exposure to diesel, petroleum fumes and fuel components such as benzene and formaldehyde contribute to cancers, acute myeloid leukemia and acute non-lymphocytic leukemia. This is not to say that the global oil industry is only known for its problems, as the industry meets humanity's energy demand. The challenge facing the global oil industry is to find a balance between the critical need for energy supply with safe and sustainable operations. Optimal site selection of these industries could minimize such challenges.

Suitability analysis for siting oil and gas filling stations have either focused on the importance of GIS-Based analysis, for example [19]-[20], or a combination of Multi-criteria Decision Analysis (MCDA) and GIS [21]-[22]. These are very useful tools for solving problems in spatial context because various decision variables can be evaluated and weighted according to their relative importance to attain the final optimal decision. The application of MCDA in siting of petrol stations has shown that accidents from filling stations have been attributed largely to oil explosions [23], spills [24], fire and leaks [25], leading to negative environmental quality, health, and safety [1], [7].

\subsection{Statement of the Problem}

The African continent at the beginning of the 20th century experienced very rapid urbanization. The cities of sub-Saharan Africa and Central Africa in particular, generally subscribing to this dynamic, have not been able to adapt their infrastructure and management structures to new urban realities. Because of its position as the economic capital of Cameroon and the heartbeat of Central Africa, Douala in Cameroon attracts many oil companies who find a wide demand for their goods there. The city has experienced significant demographic and spatial growth since independence.. This urban dynamic has not been accompanied by the establishment of adequate spatial management of petroleum product storage depots, which represents a major problem.

The government, in Order No. 39/MTPS/IMT of 26 November 1984 [26],lays down general measures of occupational health and safety at workplaces. Furthermore, in 1998, a government decree set out regulations for setting up petroleum product distribution stations. Article 4 states thus, "a minimum measurable distance must be observed between service stations and establishments, administrative buildings and places, public places, strategic location. ». The distance is in particular 1000 meters for the presidency of the republic, the services of the prime minister, the national assembly, the sub-prefectures, the stations must respect a distance of 100 meters with the educational establishments, the hospitals, places of worship, sports grounds, markets, administrative buildings, etc. Land-use planning, at its simplest, should aim at separating heavily populated areas and social infrastructures from hazardous materials and their related transport routes and at minimizing hazard exposure by building buffer zones around explosive atmospheres [27]. It is of utmost importance, in the light of the dangers posed by petrol stations, that the safety measures established in local standards are fully enforced.

However, these laws are often inadequately integrated into land-use planning, especially when it comes to site selection for the construction of filling stations. Against this context, the study was performed in order to investigate the spatial distribution of filling stations and public safety in the municipality of Douala, Cameroon. The analysis was further justified by the fact that no data on this aspect of research in the region have been published to date.

\subsection{Objectives}

This study assesses the spatial distribution of petrol filling stations in the district municipalities of Douala, and evaluates their locational compliance with national and international norms in the city of Douala. The study aims primarily to find answers to the following questions:

1) Where are petrol stations located in the City of Douala that does not meet up with necessary regulatory requirements?

2) What is the perception of the neighbouring populations with regard to the location of such stations?

3) What policy measures can be put in place to minimize the current and potential risks posed by petrol stations?

We believe that responses to these questions may help at different scales in policy making. The research results could also assist the administrative authorities of the Municipality of Douala in the implementation of comprehensive initiatives to mitigate and respond to petrol station fires, as well as in designing public awareness campaigns for communities living near petrol stations.

\section{Materials and Methods}

\subsection{Study Area}

The Douala municipality $\left(410 \mathrm{~km}^{2} ; \sim 3,600,000\right.$ inhabitants and about $13 \mathrm{~m}$ a.s.1 ), is the capital of the Littoral region, located in the estuary of the Wouri River, between $4^{\circ} 03^{\prime} \mathrm{N}$ latitude, and $9^{\circ} 42^{\prime}$ E longitude. It has six district municipalities, five of which are urban communities (Douala I-V) (Figure 1), and one (Douala VI) is a rural community.

\subsection{Methodology}

\subsubsection{Population and sample}

A two-stage sampling technic was used. First, five of the six district municipalities were selected based on whether they had petrol stations, were in the urban or rural areas. Based on these criteria, the Douala sixth district was excluded because it has no 
petrol filling stations. In the second stage, each of the five selected urban municipalities were exhaustively sampled.

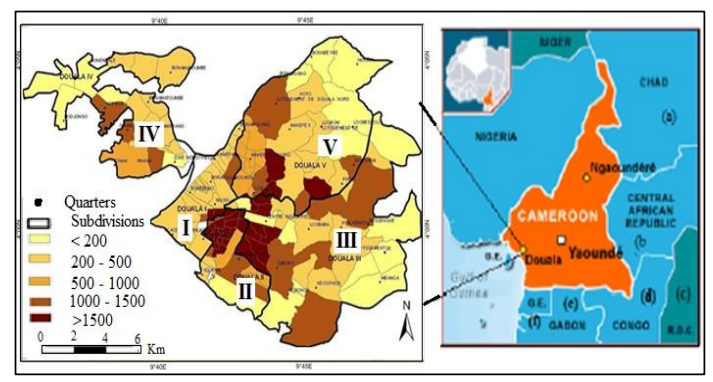

Figure 1: Location of the study area

\subsubsection{Data collection}

Data collection took place between March and April of 2020. Both primary and secondary data were collected. Secondary data were obtained from a systematic review of online databases (ISI Web of Science; CAB Abstracts; and Google Scholar, etc.) from 1990 to 2018, using locational compliance of petrol stations with standard norms and related terms as keywords. The articles were screened using inclusion/exclusion criteria applied first at the title and abstract level, and then at the full article level. Articles retained after screening underwent risk of bias assessment and data was extracted. Primary data was captured through observation and a checklist/questionnaire. The design and development of this tool included literature review, and pilot testing. At each petrol station, first, the distances from the four cardinal points (North, South, East, and West) between the station and the neighbouring dwellings were measured (Figure 2), which allowed us to obtain a stratification at different levels of concentration of the population living in the vicinity of gas stations.

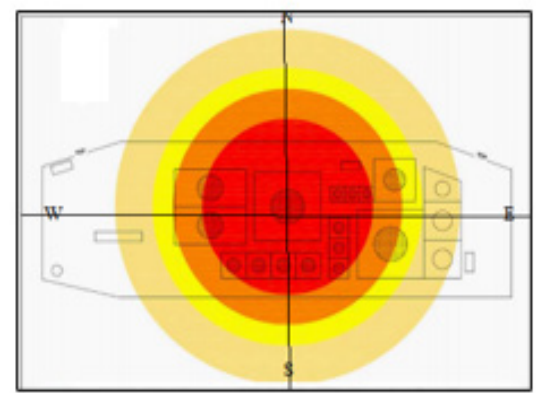

Figure 2: Stratification at different levels of concentration of the population living in the vicinity of gas stations

In the second stage, the locational characteristics (e.g., distance from green areas, a distance of pump station to the road, size of the filling stations, distance to neighbouring stations, and distance to any public facility (such as schools, churches, hospitals, market, etc.) were estimated. Finally, four residents/households, each from the four quadrats of the station were randomly selected, and their perceptions on the potential dangers associated with the proliferation of filling stations assessed. In total, $608(4 * 152)$ randomly selected household heads, located within $100 \mathrm{~m}$ radius of the inventoried filling stations were interviewed. This technic enables us to classify the stations according to the potential risk (Rp) they pose with neighbouring social infrastructures and residents, vis-à-vis existing regulations (equation 1):

$$
R_{p}=\left\{\begin{array}{c}
\text { High; if } 75-100 \% \text { not comply } \\
\text { Moderate; if } 50-74 \% \text { not comply } \\
\text { Low; if } 0-49 \% \text { not comply }
\end{array}\right.
$$

A section of the questionnaire contained multiple response question asked at each filling station to identify hazard contributing factors during operation and maintenance of filling stations.

The locations of the filling stations were captured using the Garmin Handheld GPS receivers (GPS, 62S). A section of the questionnaire was designed to capture the perception of local residents with regard to the potential threat posed to their health, properties, and the environment by their neighbouring filling stations.

\subsubsection{Data Analysis}

The software SPSS 20.0 was used to analyse the data obtained from the questionnaire. Both descriptive and inferential statistical techniques were used.. The Average Nearest Neighbour Analysis[28]-[29], using the Euclidean distance was adopted to ascertain the spatial distribution of petrol service stations in ArcGIS 10.3.1 environment, and the description of their distribution ( $\mathrm{Rn})$, defined as follows (equation 2):

where

$$
R_{n}=\frac{2 \bar{D} \sqrt{n}}{A} ; 0 \leq R_{n} \leq 2.15
$$

$\bar{D}=$ mean distance between the nearest neighbours $(\mathrm{km})$;

$\mathrm{n}=$ number of sampling points;

$\mathrm{A}=$ the area under study $\left(\mathrm{km}^{2}\right)$.

$$
R_{n}:\left\{\begin{array}{c}
1.5 \leq R_{n} \leq 2.15, \text { Dispersed } / \text { uniform } \\
0 \leq R_{n}<0.5, \text { clustered } \text { pattern } \\
0.5<R_{n} \leq 1.5, \text { Random pattern }
\end{array}\right.
$$

The Nearest Neighbor Index (NNI) is a spatial statistic that distinguishes clustered or scattered event locations in geographical patterns. The algorithm uses the distance between adjacent petrol stations to decide on their distribution pattern (random, normal or clustered). It can provide researchers with a numerical value for the clustering of a geographical phenomenon, enabling them to contrast with other locations more accurately.

\section{Results and Discussions}

\subsection{Spatial distribution of fuel stations in the City of Douala}

A total of one hundred and fifty-two (152) filling stations are unevenly distributed all over the municipalities as at the period this research was carried out. The majority of these stations, 72(47\%), are in the Douala III municipality, and the least, 11(7\%) in the Douala II municipality (Figure 3).

Most of the stations are either along major roads or in thickly populated human settlement areas, or where there are markets that can be easily accessed by customers. This is dangerous to man and the environment. On the whole, $122(80.26 \%)$ of the filling stations appear to be random in Douala I $\left(R_{n}=0.8573\right)$, Douala III $\left(R_{n}=\right.$ $0.9879)$, Douala IV $\left(R_{n}=0.6984\right)$, and, dispersed in Douala II $\left(R_{n}\right.$ $=1.7837)$ and Douala $\mathrm{V}\left(\mathrm{R}_{\mathrm{n}}=1.5764\right)$ municipalities. This kind of haphazard pattern observed in Douala I, III and IV municipalities, 
violates the fundamental objective of planning which is providing the right site for the right use at the right time for the right purpose to achieve spatial functionality, efficiency, and aesthetics.

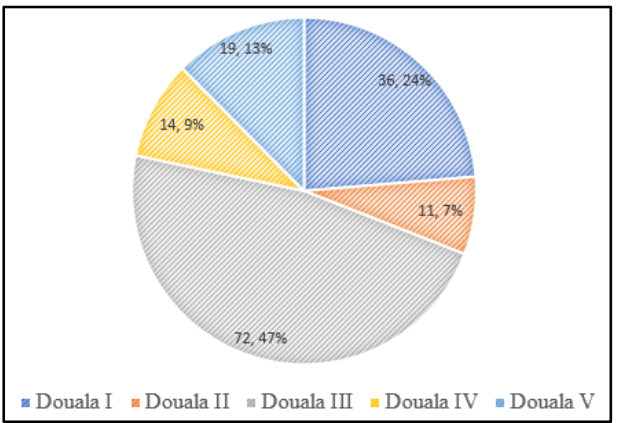

Figure 3: Distribution of petrol stations in the City of Douala

A classification of the stations according to their compliance with existing regulations, and therefore, the dangers they pose to neighbouring residents and social infrastructures (Figure 4a-e) revealed that, $23(53.49 \%)$ of those in Douala I municipality, $5(33.33 \%)$ of those in the Douala II municipality, 21 (37.5\%) of those in the Douala III municipality, $7(35 \%)$ of those in the Douala IV municipality, and $7(38.89 \%)$ of those in the Douala V municipality were not in compliance with existing regulations, and therefore pose a high risk to their neighbouring population, and social infrastructures (Residents, school buildings, hotels, hospitals, markets, etc.).

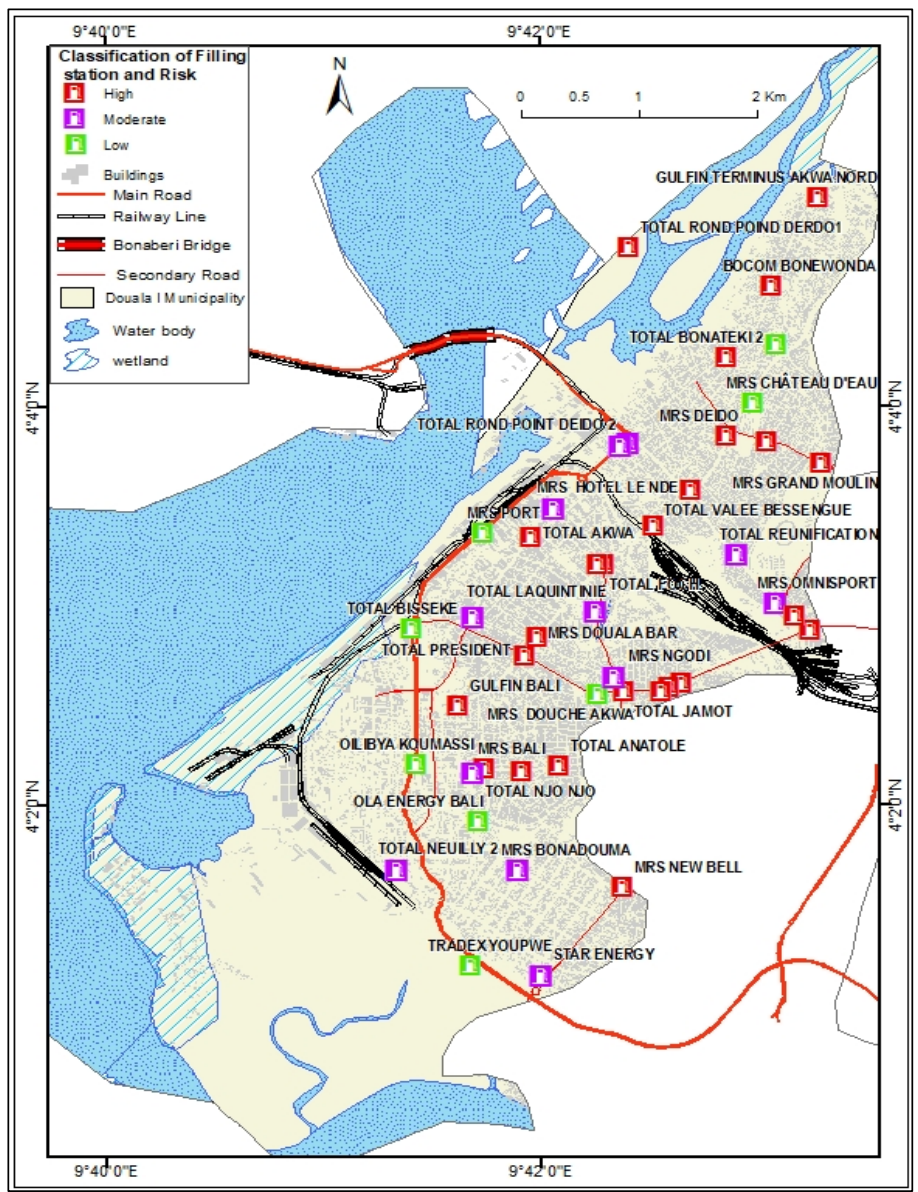

Figure 4 (a): Patterns and risk prone stations in the Douala I

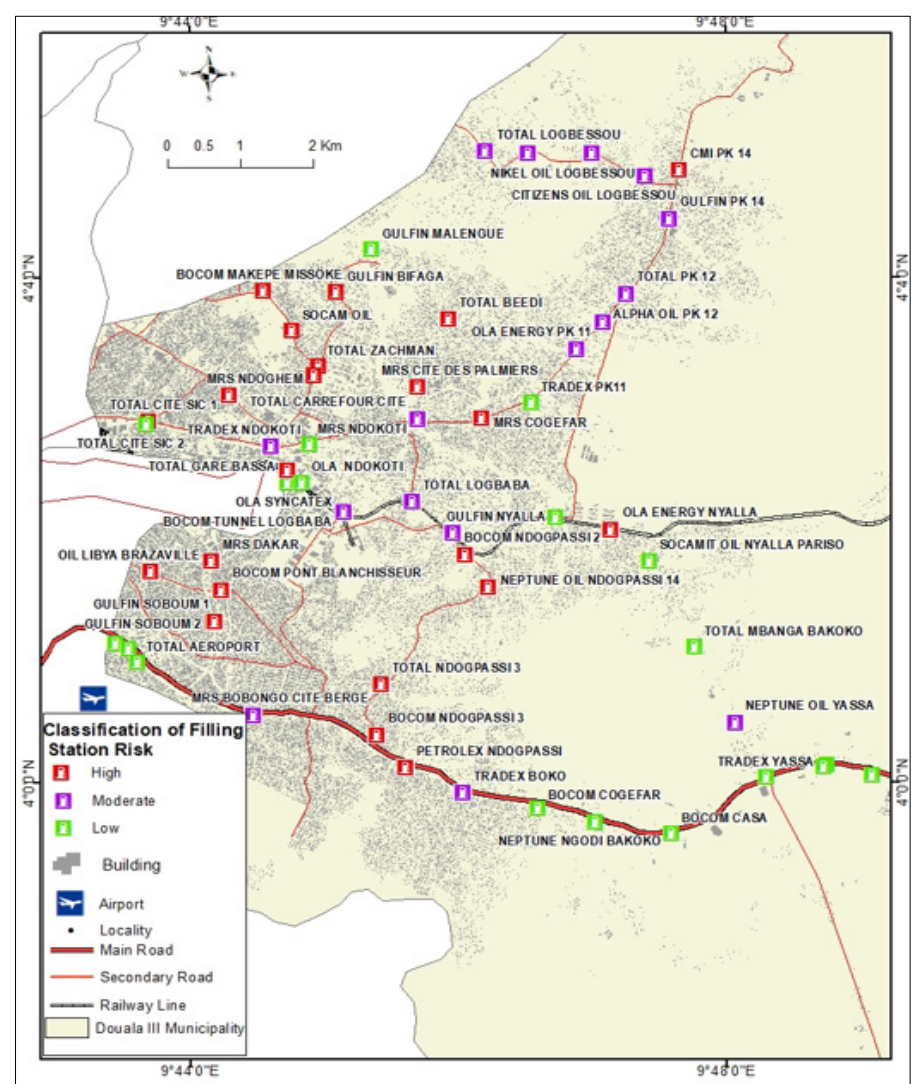

Figure 4 (b): Patterns and risk prone stations in the Douala III

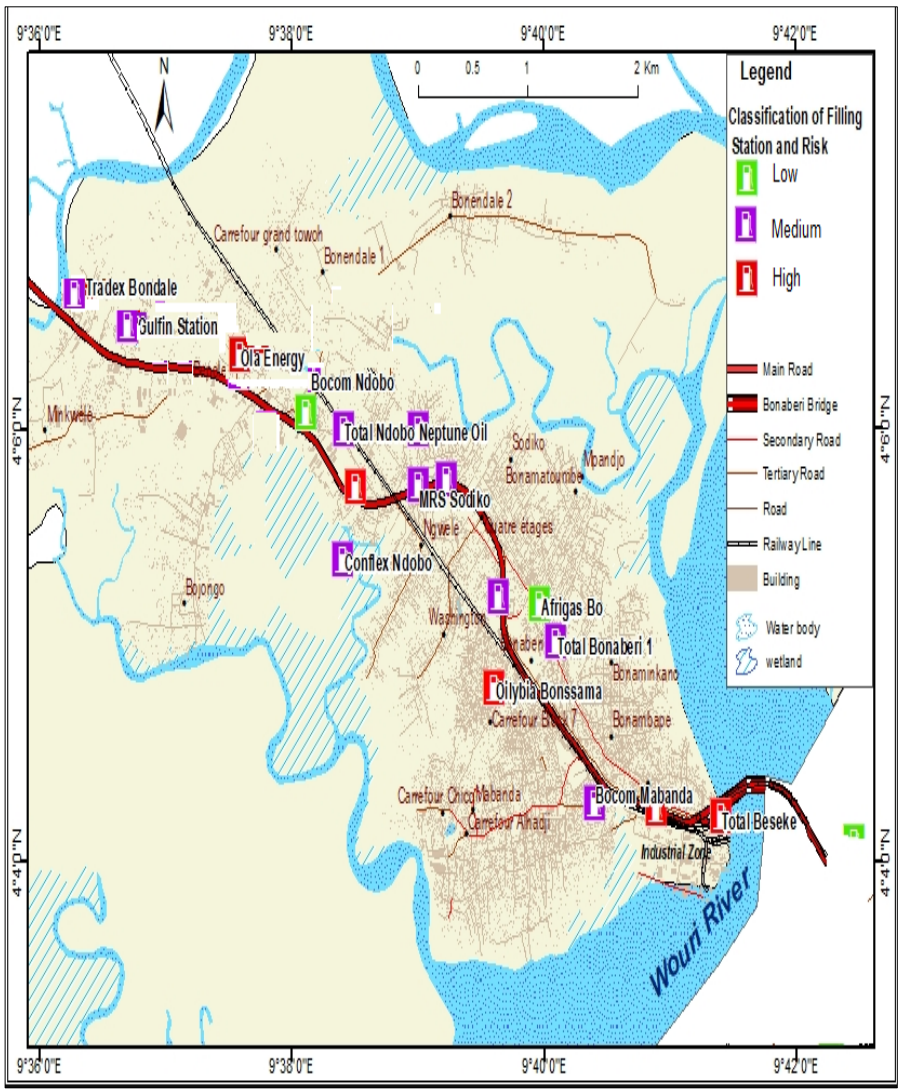

Figure 4 (c): Patterns and risk prone stations in the Douala IV 


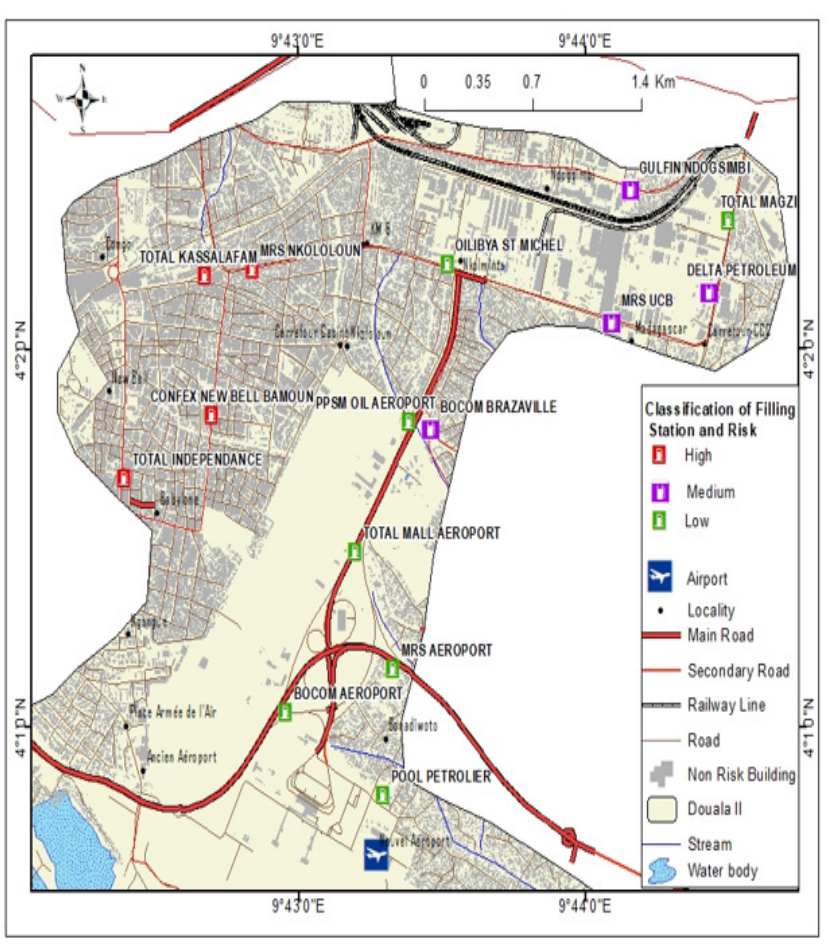

Figure $4(\mathrm{~d})$ : Patterns and risk prone stations in the Douala II

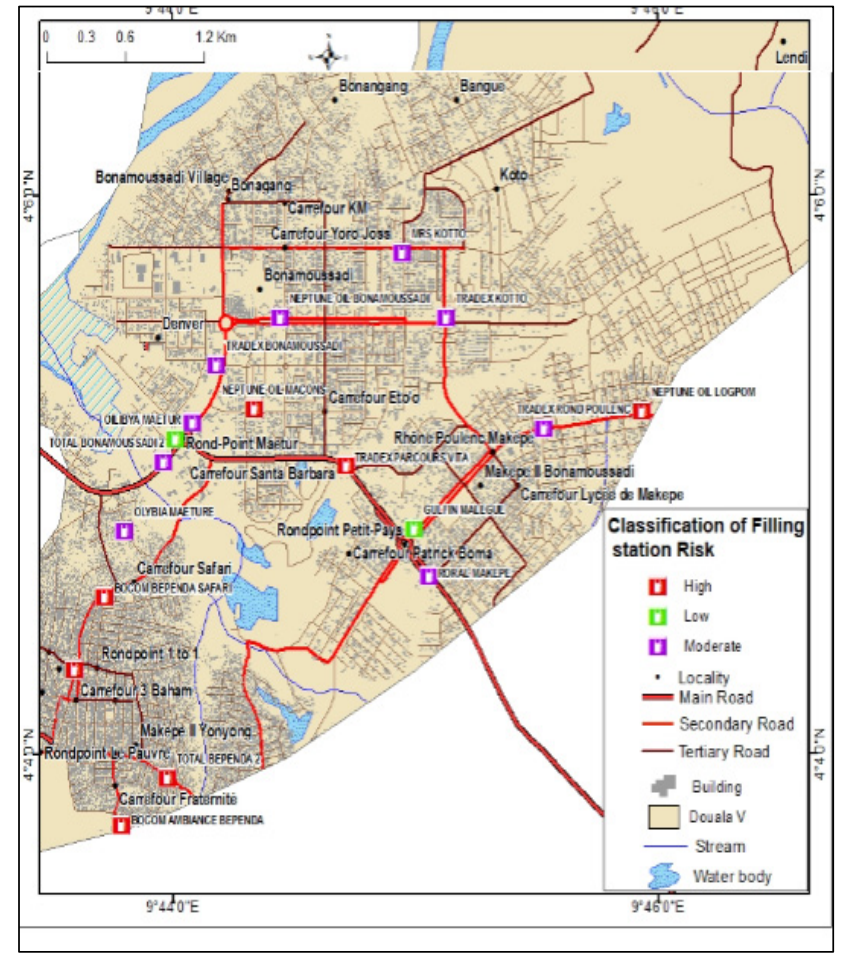

Figure 4 (e): Patterns and risk prone stations in the Douala V

\subsection{Compliance of petrol stations with development good practices}

\subsubsection{Distances between filling stations}

Most of the stations, 94 (61.84\%) were within the minimum $500 \mathrm{~m}$ radius as specified by the law. Of these stations that, 55 $(58.51 \%)$ were found in the Douala III district, while the least number, 4(4.26\%) were from Douala II district (Figure 5)

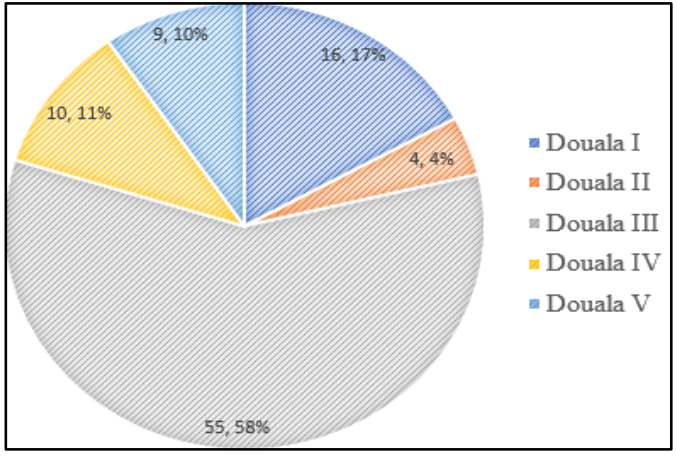

Figure 5: Petrol stations within the minimum $500 \mathrm{~m}$ radius in the City of Douala

\subsubsection{Distances between filling stations and main road}

Of the 152 stations investigated, only one $(0.66 \%)$ was within the stipulated distance of $7 \mathrm{~m}$ between the edges of a station, and a major road. The rest, $99.34 \%$ were between 1 and $3 \mathrm{~m}$. This partly explains the rising road traffic problems such as a traffic congestion, breaches of traffic law, and road traffic accidents that have over the years disrupted the city's economic activities. It also poses questions about the threats posed to nearby communities and pedestrians by the fumes (volatile organic compounds) released from operational activities of the stations.

\subsubsection{Distance of Filling Stations to Health Facilities}

Of the 152 petrol stations sampled in the municipality, 126 $(84 \%)$ were located within the stipulated $100 \mathrm{~m}$ radius $\left(\mathrm{X}^{2}(48)=\right.$ $71.442 ; p=0.016)$ as specified by law. Of these, $24(66.78 \%)$, were from Douala I, 10 (90.9\%) were from Douala II, $64(88.9 \%)$ were from Douala III, 10(83.3\%) were from Douala IV, and 18 (94.9\%) were from the Douala V district. The study shows that most hospitals are conveniently situated far away from gas stations. Most of the 26 stations that did not comply with the current regulations were located in Douala I, (50\%) and Douala IIII (33.33 $\%)$. It should be noted that Douala I is the Wouri Division's administrative headquarters and is the oldest municipality in Douala. On the other hand, the largest and most populous municipality is Douala III. The likely reason for these playouts may be due to the market along these areas, and the fact that regulators bend to this rule and give a waiver to the filling stations.

\subsubsection{Distance between filling stations and educational establishments}

Based on legal requirements, petrol stations are not allowed to operate adjacent to public institution like schools. However, should there be a need, the facility should be within $100 \mathrm{~m}$ radius of a school environment. Our findings showed that, overall, $119(79.3 \%)$ of the stations in the entire municipality complied. Of these, 31(86.1\%) were from Douala I, $10(90.9 \%)$ were from Douala II, 56 (77.8\%) were from Douala III, $8(66.7 \%)$ were from Douala IV, and 14 (73.7\%) were from Douala V. Of the 33 (21.3\%) that did not comply, 17 (51.52\%) were from Douala III, 5 each (15.15\%) from Douala I and II, 4(12.12\%) from Douala IV, and 2(6.06\%) from Douala V district.

\subsubsection{Distance between filling stations and the market places and human settlements}

According to national guidelines, residential buildings, schools or hospitals should not be within 100 meters of gas stations unless 
it can be clearly shown there would be no effect concerning noise, visual interference, safety considerations or smells and fumes. The analysis suggests, however, that several petrol stations have breached this law. For example, most of the stations, 144 (94.74\%) in the municipality were not within a 100 -m radius from markets. Likewise, most of the stations, 127 (83.55\%) were within $40 \mathrm{~m}$ of human settlements, which is much less than the $100 \mathrm{~m}$ required by law (Figure 6).

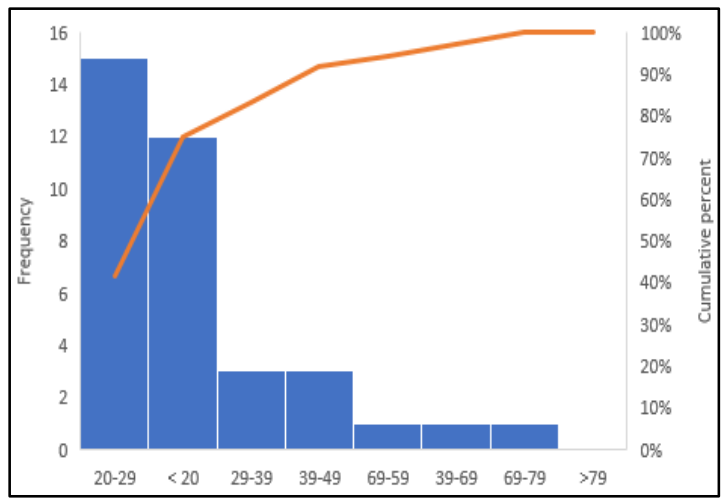

Figure 6: Distances of filling stations to human settlements

The stations therefore seem to have high potential of hazards (hydrological, geological, socio-economic, etc.) to their surroundings. The main contributors to cancers, acute myeloid leukemia, and acute non-lymphocytic leukemia have been described as exposure to diesel, petroleum fumes, and fuel components such as benzene and formaldehyde [4]. Good practice globally prohibits construction in the vicinity of gas stations, in particular hospitals, community centres, schools and old people's homes and housing [29].

These results indicate that the existing model and regulations for land use do not consider the fire threat raised by petrol stations and do not protect the public sufficiently. While there has never been a major fire at a gas station in the municipalities of Douala, a municipal explosion or fire could potentially lead to significant damage and even death and injury. Even in the moderate risk areas of the municipality, human settlement and the construction of schools and hospitals are ongoing. Given the current rate of urban sprawl and the poor implementation of government rules and regulations resulting from overall bad governance culture in the country, it is hard to estimate when the economy-ecology balance shall be taken into consideration in the city's development plan.

Nevertheless, the Douala municipalities are not unique when it comes to adhering to best practices. Similar results had been obtained elsewhere, for example, [30] and [31]. The latter pointed out that the common issue of all urban settlements today is erratic and unsound urban growth, and that the increasing continuation of this problem is unavoidable in this order, in which the balance between the economy and the environment is not taken into account and economic interests often win. While the reasons can vary, the most common ones concern the economic benefits to the local community and municipality of the petrol stations [4].

\subsection{Hazard contributing factors in the operation and maintenance of filling stations in the municipalities}

Several hazard contributing factors that have the potential to create unsafe conditions in the functioning of the filling stations in the municipality were reported. In order of priority they include miscellaneous cases, 152(25.63\%); slips, trips \& falls, 126(20.1\%); carelessness 98(16.53\%), transportation, 84(14.17\%), electrical faults, $67(11.30 \%)$, fire risk, $49(8.26 \%)$ and medical treatment 17(2.87\%) (Figure 7).

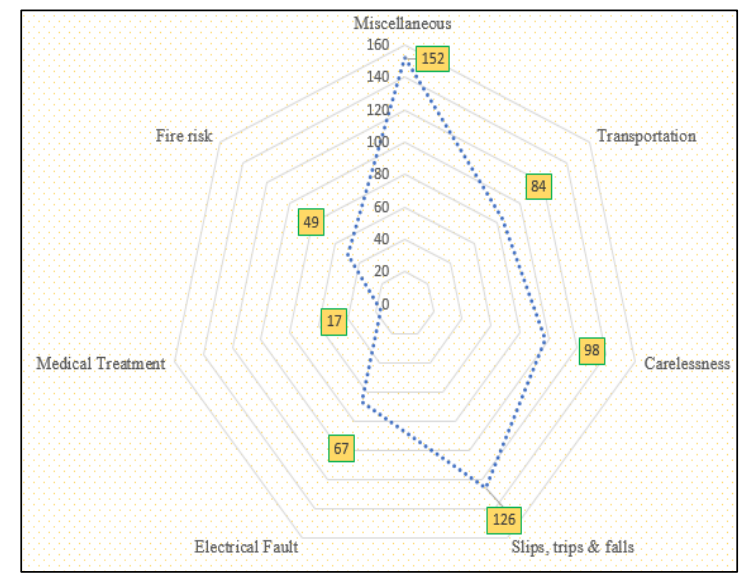

Figure 7: Prioritized hazardous activities at petrol stations

Miscellaneous cases comprised of hazard contributing factors such as oil spillages, water leakages, robbery, law and order situation, and, maintenance issues. The numerous unsafe practices that were recorded in many of the filling stations could be attributed to inadequate safety procedures by staff, failure to clear oil spills, unsafe manual handling practices and the storage of fuel samples in unmarked containers.

Slips, trips \& falls could be as a result of oil leakage. This suggests poor supervision and inadequate training. Simple prevention steps such as education and health and safety training are often ignored. Hence, occupational health services and supporting legislation need refocusing, revision and reinforcement. On the other hand, carelessness can be due to a variety of causes, including, though not limited to, the unsatisfactory use of staff protective equipment, the use of mobile phones in the tank area, and the insufficient use of signs and instructions.

\subsection{Residents' perceptions of the possible hazards associated with the emergence of refueling stations}

A significant $77 \%$ of the respondents perceived that the distances between some of the filling stations were inadequate. A smaller percentage, $61 \%$ percentage stated that the distances between the filling stations and the places of public assemblies were inadequate, while $58 \%$ perceived that the distances between adjacent filling stations were inadequate. (Figure 8).

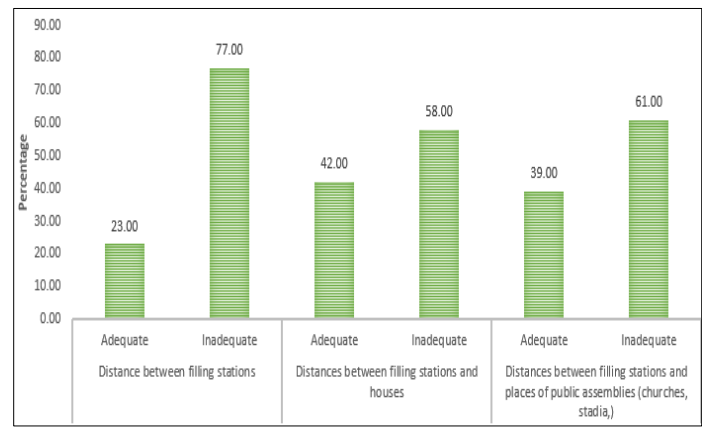

Figure 8: Perception of locals of the adequacy of the siting of stations 
The breaches of the appropriate distances between the filling stations, the distances between the filling stations and the nearest public assembly houses/places are strong indications of pressing concerns about the health and safety hazards presented by these petrol filling stations (PFS) and the risks to which residents are prone[7]. In the Douala municipalities, it is common to either see people acquiring lands very close to PFS to create residential homes and/or other businesses, or PFS being established at unacceptable distances from the population and social infrastructures.

A significant number of the respondents $(74.25 \%)$, most of them from the Douala III district were aware of the proliferation of petrol filling stations in their communities together with the associated dangers and health hazards they pose (Figure 9). Those who were not aware of these proliferations are relatively new to the areas, while those who were aware of these proliferations have been living in the areas for more than two decades.

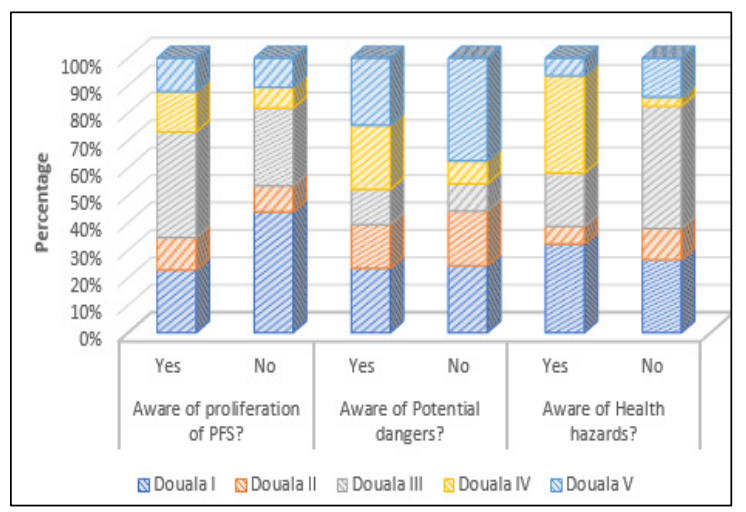

Figure 9: Level of awareness of locals of the potential dangers associated with fuel stations

Those who were aware of the potential health hazards of petrol fueling stations mentioned respiratory diseases as a result of chronic exposure to dust $(26.37 \%$ of respondents), chronic exposure to volatile organic compounds (36.62\%), and chronic exposure to vehicle exhausts (37.12\%). Other findings, such as [32], have shown that petrol vapor could find its way into the basements of buildings and public drains with significant implications if the vapor comes into contact with the ignition source. Many other studies have also reported that fuel stations provide acceptable grounds for fire outbreaks and expose several physical, chemical and ergonomic threats to employees and residents [33].

While a large number of residents were aware of the possible dangers associated with fuel stations, no action was taken to resolve their concerns by the local administrative authorities. This could be viewed as a failure by local authorities and regulatory agencies to proactively resolve (in a participatory way) the problems of the haphazard proliferation of petrol stations against the context of the various possible risks and hazards associated with stations across the municipalities. Building on existing social awareness as such has been identified as a key catalyst towards the achievement of the Sustainable Development Goals [34].

\section{Conclusion}

In the above-mentioned discussion, the degree to which the location and operation of petrol stations in the City of Douala, Cameroon, compares with relevant current regulations and the consequences for public safety has been examined. A hybrid methodology was used that incorporated both explicit and implicit data from field investigations. The approach is comparable to other heuristic methods. In some cases, it can be considered as a realtime and reliable detection approach, and offers a strong potential for better understanding and investigating of the environment especially in regions such as sub-Saharan Africa, where existing petrol station databases are uncommon and often unreliable. The implementation of this approach has shown that the location of petrol stations in the City of Douala do not completely comply with the guidelines of good practice. Furthermore, the study shows that the haphazard emergence of municipal filling stations is laden with possible health, safety and environmental risks that could be blamed on the inability of government regulatory bodies to implement established laws and policies effectively. If a good mapping of the issue to an acceptable network architecture is identified, this method can also be used to assess hazardcontributing factors and the awareness of residents in detail. In the future, this might be a fascinating place for research. The results trigger the need for local governments to inculcate the interest of the resident population and employees of petrol stations as a core concern in projects that directly affect local ecosystems. Local administrative authorities also need to take timely action to ensure that: (a) an environmental and social audit is carried out before a petrol station is constructed to ensure that it complies with local and./or international standards, and (b) people are prohibited from purchasing land for schools, markets, etc., near filling stations or near filling stations to create residential homes, etc.

\section{Conflict of Interest}

The authors declare no conflict of interest.

\section{Acknowledgments}

We acknowledge the government of Cameroon for her constant financial assistance to research.

\section{References}

[1] F. Monney, I., Dramani, J. B., Aruna, A., Tenkorang, A. G., \& Osei-Poku, "Health and safety in high-risk work environments: A study of fuel service stations in Ghana," Ournal of Environmental and Occupational Scienc, 4(3), 132-140, 2015, doi:10.1016/j.jlp.2005.05.015.

[2] P. V. Chaiklieng S., Dacherngkhao T., Suggaravetsiri P., "Fire risk assessment in fire hazardous zones of gasoline stations," Journal of Occupational Health, 62(1), 2020, doi:10.1002/1348-9585.12137.

[3] B.C. Thomas Kweku Taylor, Chanda Sichinsambwe, "Public Perceptions on Location of Filling Stations in the City of Kitwe in Zambia.," Developing Country Studies, 6(6), 133-151, 2016.

[4] E. Mshelia, M., Abdullahi, J. and Dawha, "Emmanuel. Environmental effects of petrol stations at close proximities to residential buildings in Maiduguri and Jere, Borno State, Nigeria.," IOSR Journal of Humanities and Social Science (IOSR-JHSS), 20(4), 1-8, 2015. doi:10.1016/j.36898.05.015.

[5] D.N. Mohammed, M.U., Musa, I.J., and Jeb, "GIS-Based Analysis of the Location of Filling Stations in Metropolitan Kano against the Physical Planning Standards.," American Journal of Engineering Research, 3(9), 147-158, 2014.

[6] S.M. Nouri, J., M. Omidvari, and Tehrani, "Risk Assessment and Crisis Management in Gas Stations,” Int. J. Environ. Res., 4(1), 143-152, 2010.

[7] P.M. Nieminen, Environmental Protection Standards at Petrol Stations: A Comparative Study of Technology between Finland and Selected European Countries. Thesis for the Degree of Doctor of Technology, Tampere University, Finland., 2005.

[8] S. Ayodele, Spatial Distribution of Petroleum Filling Station in Kaduna North.

[9] Timothy J.S. et al, "Air pollution success stories in the United States: The 
value of long-term observations," Environmental Science and Policy, 84(November 2017), 69-73, 2018, doi:10.1016/j.envsci.2018.02.016.

[10] British Broadcasting Corporation (BBC), Ghana petrol station fire: Accra death toll tops 150 after inferno during severe flooding. Online at https://www.independent.co.uk/news/world/africa/ghana-petrolstation- fireaccra-tops-150-die-petrol-station-explosion-during-ghanaflooding10299432. Acces, Accessed on 10/10/2020., 2015.

[11] GhanaWeb, "One more dead as Krofrom gas explosion death toll rises to 2," Http://Mobile.Ghanaweb.Com/GhanaHomePage/NewsArchive/OnemoreDead-AsKrofrom-Gas-Exposion-Death-Toll-Rises-to-2- 702607, 2015.

[12] S. FK, "Fires and related incidents in Jordan (1996-2004)," Fire Safety J., 41(5), 370-376, 2006.

[13] M.M. Ahmed, S.R.M. Kutty, A.M. Shariff, M.F. Khamidi, "Petrol Fuel Station Safety and Risk Assessment Framework," DOI: 10.1109/NatPC.2011.6136346, 2011, doi:10.1109/NatPC.2011.6136346.

[14] T.S.\& S. Seyhan, "A Multi-Criteria Factor Evaluation Model For Gas Station Site," Journal of Global Management, Global Research Agency, 2(1), 12-21, 2011.

[15] O. Ogunyemi, S.A., Ajileye, O.O., Muibi, K.H., Alaga, A.T., Eguaroje, O.E., Samson, S.A., Ogunjobi, G.A., Adewoyin, J.E., Popoola, O.S., Oloko-Oba, M.O. and Omisore, "Geo-Information and Distribution Pattern of Petrol Service Station in Sango - Ota Metropolis in Ado - Odo Ota Local Government Area, Ogun State, Nigeria," Asian Research Journal of Arts \& Social Sciences, 2(1), 1-11, 2017.

[16] J.A.O. Arokoyu Samuel B., Ogoro Mark, "Petrol filling stations' location and minimum environmental safety requirements in Obio Akpor lga, Nigeria," International Journal of Scientific Research and Innovative Technology, 2(11), 2015.

[17] K. H, Markus, AM, Bernat, N, Jian, MR, Ana, EN, "Hydrocarbon Release During Fuel Storage and Transfer at Gas Stations: Environmental and Health Effects," Current Environmental Health Reports, 2(4), 412-422, 2015.

[18] R. C. T Tanaka, T Azuma., J.A Evans., P.M Cronin., D.M Johnson., "Experimental study on hydrogen explosions in a full-scale hydrogen filling station model," Int. J. Hydrogen Energ, 32, 2162 -2170, 2007.

[19] K. Emakoji, M.A, \& Otah, "Managing Filling Stations Spatial Database Using an Innovative GIS Tool - Case Study Afipko City in Nigeria," Asian Journal of Geographical Research, 1(2), 1-9, 2018.

[20] I.J.M. Broekhuizen, H., Groothuis-Oudshoorn, C.G., van Til, J.A., Hummel, J.M., "A review and classification of approaches for dealing with uncertainty in multi-criteria decision analysis for healthcare decisions," Pharmacoeconomics, 33(5), 445-455, 2015. doi:10.1016/j.2015.05.01265.

[21] J. Boroushaki, S., and Malczewski, "Implementing an extension of the analytical hierarchy process using ordered weighted averaging operators with fuzzy quantifiers in ArcGIS," Computers \& Geosciences, 34(4), 399410, 2008 .

[22] Z. Aneziris, O. N., Papazoglou, I. A., Konstantinidou, M., \& Nivolianitou, "Integrated risk assessment for LNG terminals," Journal of Loss Prevention in the Process Industries, 28, 23-35, https://doi.org/10.1016/j.jlp.2013.07.014.

[23] C.-C.L. James Chang, "A study of storage tank accidents," J. Loss Prev. Process Ind., 19, 51-59, 2006, doi:10.1016/j.jlp.2005.05.015.

[24] N. Cao, M. Štěpnička, M. Burda, "Fuzzy Quantifiers and Compositions of Partial Fuzzy Relations Employing Dragonfly Algebras," in 2019 IEEE International Conference on Fuzzy Systems (FUZZ-IEEE), 1-6, 2019, doi:10.1109/FUZZ-IEEE.2019.8858832.

[25] A. Hailwood, M., Gawlowski, M., Schalau, B., \& Schoenbucher, "Conclusions drawn from the Buncefield and Naples incidents regarding the utilization of consequence models," Chemical Engineering \& Technology: Industrial Chemistry-Plant Equipment-Process Engineering-Biotechnology, 32(2), 207-231, 2009.

[26] C. Ministry of Labor and Social Welfare, Order No. 39 / MTPS / IMT of November 26, 1984 laying down general health and safety measures in the workplace., $\quad$ Offprint, https://www.ilo.org/dyn/natlex/natlex4.detail?p isn=39672\&p lang=e.

[27] I.R.C. (IRC), Recommended practice for locating and layout of roadside motor-fuel filling and motor-fuel fillingcum service stations (IRC),[Online].pbhousing.gov.in/notification_files/Petrol_Pumps((IRC(121 983))75.pdf; Accessed 12/6/2020., 2009.

[28] A. Mitchell, ESRI Guide to GIS Analysis, 2 (Spatial Measurements and Statistics) 1st Edition, 2005.

[29] E. David, Statistics in Geography, Blackwell, 1985.

[30] K. Qonono, Analysis of the fire hazard posed by petrol stations in Stellenbosch and the extent to which planning acknowledges risk, Stellenbosch University.

[31] M. Brueckner, J. K., Mills, E., \& Kremer, Urban sprawl: Lessons from urban www.astesj.com economics [with comments], 2001

[32] R. Sakyi, P.A., Efavi, J.K., Atta-Peters, D., Asare, "Ghana's Quest for Oil and Gas: Ecological Risks and Management Frameworks.," West African Journal of Applied Ecology, 20(1), 57-72, 2012.

[33] E.E.Y. Douti, N. B., Abanyie, S.K., Ampofo, S., \& Amuah, "Spatial distribution and operations of petrol stations in the Kassena-Nankana district (Ghana) and associated health and safety hazards," Journal of Toxicology and Environmental Health Sciences, 11(5), 50-61, 2019.

[34] S.R. Mensah, J., \& Casadevall, "Sustainable development: Meaning, history, principles, pillars, and implications for human action: Literature review.," Cogent Social Sciences, 5(1), 2019. 